\title{
FREEZING OF SPUTUM AS A WAY TO IMPROVE THE APPLICABILITY OF SPUTUM STUDIES
}

\author{
Todor A. Popov ${ }^{*}$, Aleksandar Petlichkovski², Tihomir B. Mustakov ${ }^{3}$, and Tanya Z. Kralimarkova ${ }^{3}$ \\ ${ }^{1}$ University Hospital St. Ivan Rilski, Sofia, Bulgaria \\ ${ }^{2}$ Institute for Immunobiology and Human Genetics, Faculty of Medicine, Stt. Kiril and Metodij \\ University, Skopje, FYROM \\ ${ }^{3}$ Clinical Center Allergology, Medical University, Sofia, Bulgaria
}

Rationale: Sputum examination is a valuable research tool to study airway diseases, but the requirement to process the samples within 2 hours of their collection poses limitations to its wider applicability. A way to bypass this hurdle would be to freeze the sample at the time of collection and to examine it at a later stage.

Methods and Subjects: We developed a protocol for freezing of sputum upon collection by adding dimethylsulfoxide to it. We tested the reproducibility of cell counts in frozen samples and in fresh portions from the same sputum specimens. We took sputum from 41 asthmatics (18 males) with different levels of control of their disease: 19 of the samples were spontaneously produced and 22 were induced with hypertonic saline.

Results: Significant correlations $(p<0.05)$ were established between the total cell counts, the relative and absolute number of neutrophils, eosinophils and macrophages in the paired fresh and frozen sputum samples. Cell viability in frozen sputum was slightly but consistently lower. Only one frozen sample had viability $<50 \%$. Outcomes in paired samples from induced sputum had better reproducibility than the spontaneous ones.

Conclusion: Examination of frozen sputum samples does not change total cell counts and differential cell counts, despite consistently affecting cell viability compared with fresh sputum cellularity. Still cell viability in frozen sputum was above $50 \%$ in all but one examined specimens. Biomed Rev 2018; 29: 83-88

Keywords: sputum, cellular content of sputum, frozen sputum, induced sputum, asthma, COPD

Received 15 December 2018, revised 21 December 2018, accepted 21 December 2018.

*Correspondence to: Dr Todor A. Popov, University Hospital St. Ivan Rilski, Sofia, 13 Urvich Str., BG-1612 Sofia, Bulgaria. Phone: +359-2-4519438, Cellular:+359-88-5329907. E-mails: ted.popov@gmail.com; tedpop@rtb.mu-sofia.bg 


\section{INTRODUCTION}

Sputum is formed into the lower airways and is expected to reflect their condition in health and disease. Some 100 years ago this rationale sparked the interest of Harry Morrow Brown, who found that asthmatic patients with eosinophils in their sputum readily respond to prednisolone (1). In the following years continuing attempts had been made to differentiate between asthma and chronic bronchitis on the basis of microscopical chemical analysis of sputum (2-4). However, it was only in the 90s of last century that the method of sputum examination was upgraded and proven to be reliable, valid and feasible in studying airway diseases. The crucial breakthrough came as a result of introduction in the sputum processing protocol of a step meant to disengage the sputum cells from their glycoprotein matrix (5-7). This made possible quantitative evaluation of all cellular components in sputum, thus characterizing more thoroughly pathogenic mechanisms in asthma, other airway diseases and their variants. Differential cell counts (DCC) of sputum cells turned out to be the most important determinant of various disease states and the level of control of airway inflammation. Actually, most sputum studies focused on the cellular content and sputum soluble markers played an auxiliary role. With the highlight on sputum cells, an important concept was reinforced that sputum samples induced by inhalation of hypertonic saline aerosols had higher cell viability and better quality of the end cellular suspensions than spontaneous sputum samples (8).

Sputum induction and examination withstood the test of time and imposed itself as a valuable tool in clinical research $(9,10)$. However, there are certain limitations to the wider applicability of sputum studies in clinical practice. Among them is the requirement to process the samples within the first 2 hours of their collection in order to get reliable cell counts. This certainly is a problem when sputum is to be collected away from the processing lab. A way to bypass this hurdle would be to freeze the sample at the time of collection and examine it at a later stage at the convenience of the investigators.

We have developed a protocol for sputum freezing on collection and subsequent processing. We needed to investigate the applicability of this approach by comparing it to the standard procedure used until now. We are limiting ourselves to cellular outcomes, as cells are most likely to suffer from the freezing and thawing procedure.

\section{METHODS}

\section{Subjects}

Forty-one subjects (18 males) from among the asthmatic subjects volunteered to provide sputum samples for this study. All of them signed informed consent forms in conformity with the principles of Good Clinical Practices and the Declaration of Helsinki. They were with different levels of control of their asthma as judged by the severity of their symptoms, spirometry, and peak exspiratory flow rate (PEFR) monitoring. None of them was severely ill, 15 (36.6\%) had evidence of atopy, 13 (31.7\%) were non-smokers, 9 (22.0\%) were smokers, and 19 (46.3\%) ex-smokers. Nineteen of them were able to expectorate sputum spontaneously, while in the rest 22 patients, sputa were induced with inhalation of 3, 4 and 5\% hypertonic saline. All patients signed informed Ethics Committee approved consent forms in conformity with the principles of Good Clinical Practices and the Declaration of Helsinki.

\section{Laboratory measurements}

Sputum induction. Sputum induction was performed as described earlier in detail (11). Briefly, after baseline spirometry and pretreatment with salbutamol, subjects inhaled 3, 4 and $5 \%$ hypertonic saline for 7 minute periods. After each period they tried to cough out sputum into plastic containers.

Sputum freezing and storage. Right after collection the sputum specimens were poured into Petri dishes and the portions originating from the lower airways were selected and put into Eppendorf tubes. After putting aside the part of the specimen to be processed without delay, $100 \mu \mathrm{L}$ of dimethyl sulfoxide (DMSO, Merck, Germany) were added to the tube. The tubes were then sealed, shaken vigorously by hand for 30 seconds, coded, and stored in a freezer at $-70^{\circ} \mathrm{C}$.

Sputum processing. Fresh sputum samples were processed within 30 minutes after collection, following the established protocol. The frozen sputum samples were processed, after being kept at $-70^{\circ} \mathrm{C}$ for at least two days. We used a previously described protocol with slight modifications. The Eppendorf tubes were left at room temperature to thaw and weight of their content was measured. Ten times diluted solution of dithiothreitol (DTT) (Sputalysin, Calbiochem Corp., La Jolla, $\mathrm{Ca}$ ) was added to the sputum in a four times bigger volume (in $\mu \mathrm{L}$ ) than the sputum weight (in $\mathrm{mg}$ ). The mixture was well homogenized by vortexing for 30 seconds and rocking for 15 minutes. Addition of Delbecco phosphate buffered saline (D-PBS) equal in volume to the DTT followed, after which the suspension was filtered through a $53-\mu \mathrm{m}$-pore nylon filter (Spectrum, TX, USA). After centrifugation at $1000 \mathrm{rpm}$ for 10 minutes, the cell pellet was resuspended in $0.4 \mathrm{ml}$ D-PBS. Cell viability was assessed by trypan blue exclusion using Burker's hemocytometer and total cell count $(\mathrm{TCC})\left[\times 10^{\wedge} 3\right.$ cells per mg of sputum] was calculated on the basis of the 
hemocytometer count, taking into consideration the overall dilution. Cytospins were made from the resuspended material using a Hettich Universal cytocentrifuge (Tuttlingen, Germany). They were methanol fixed and stained using the May-Grunwald Giemsa. Differential counts were made on the basis of 400 non-squamous cells by two observers, blinded to the origin of the separate slides and the objectives of the study.

The frozen sputum samples were processed according to the same protocol after leaving the Eppendorf tubes at room temperature to thaw. All subsequent dilutions took into account the $100 \mu \mathrm{L}$ DMSO added before freezing the specimen.

\section{Data analysis}

Descriptive statistics were used to characterize the subjects in the study. Reliability Analysis procedure was used to compare the measurements in fresh and frozen sputum. It provided information about the relationships between individual items in the paired samples. Intraclass correlation coefficients were computed as a measure of reproducibility / reliability of the measurements. Variables characterizing the fresh and the frozen sputum samples were also correlated using Pearson's coefficient, and also both Student's paired t-test and F-statistics of the analysis of variance (data with suspected non-normal distribution as in the case of sputum eosinophils, neutrophils and macrophages were log-transformed for this purpose). A two-tailed probability $\mathrm{p}<0.05$ was considered statistically significant. Calculations were done by means of SPSS for Windows software.

\section{Results}

Significant correlations were established between the total cell counts (TCC), the relative and absolute numbers of neutrophils, eosinophils and macrophages in the fresh and frozen sputum samples (Table 1).

The numbers (both relative and absolute) of lymphocytes and bronchial epithelial cells were too low to allow sensible statistical inferences.

There were no significant differences between the number of total cell counts and the number of eosinophils, neutrophils and macrophages of the fresh and frozen samples. However, there was a small but significant difference between the viability of the cells: the viability of the cells in the frozen sputum was consistently lower (Fig. 1). However, only one frozen sputum sample had viability below $50 \%$.

We analyzed the same outcomes separately for the spontaneous and the induced sputum paired samples. This stratification did not bring about major differences from the major layout, but the level of consistency of counts in the induced sputum samples was somewhat better, reaching also a statistically significant correlation between the viability percentage of fresh and frozen specimens (Table 2).

Quality of the slides did not significantly differ between fresh and frozen sputum samples. The quality of bot fresh and frozen induced sputum samples was superior to the quality of the fresh + frozen spontaneously coughed out sputum specimens.

Table 1. Relationships between different cellular characteristics of paired fresh and frozen sputum samples.

\begin{tabular}{|c|c|c|c|c|c|}
\hline $\begin{array}{l}\text { Paired samples } \\
\text { fresh / frozen sputum }\end{array}$ & $\mathbf{N}$ & $\begin{array}{l}\text { Pearson's } \\
\text { correlation } \\
\text { coefficient }\end{array}$ & Sig. $P$ & $\begin{array}{l}\text { Intraclass } \\
\text { correlation } \\
\text { coefficient }\end{array}$ & Sig. $P$ \\
\hline TCC & \multirow{8}{*}{41} & 0.322 & 0.040 & 0.49 & 0.019 \\
\hline Viability & & 0.202 & 0.205 & 0.32 & 0.115 \\
\hline$\%$ neutrophils & & 0.592 & 0.001 & 0.74 & 0.000 \\
\hline $\begin{array}{l}\text { Absolute number of } \\
\text { neutrophils }\end{array}$ & & 0.333 & 0.034 & 0.48 & 0.020 \\
\hline$\%$ eosinophils & & 0.871 & 0.001 & 0.92 & 0.000 \\
\hline $\begin{array}{l}\text { Absolute number of } \\
\text { eosinophils }\end{array}$ & & 0.781 & 0.001 & 0.88 & 0.000 \\
\hline$\%$ macrophages & & 0.631 & 0.001 & 0.77 & 0.000 \\
\hline $\begin{array}{l}\text { Absolute number of } \\
\text { macrophages }\end{array}$ & & 0.691 & 0.001 & 0.73 & 0.000 \\
\hline
\end{tabular}




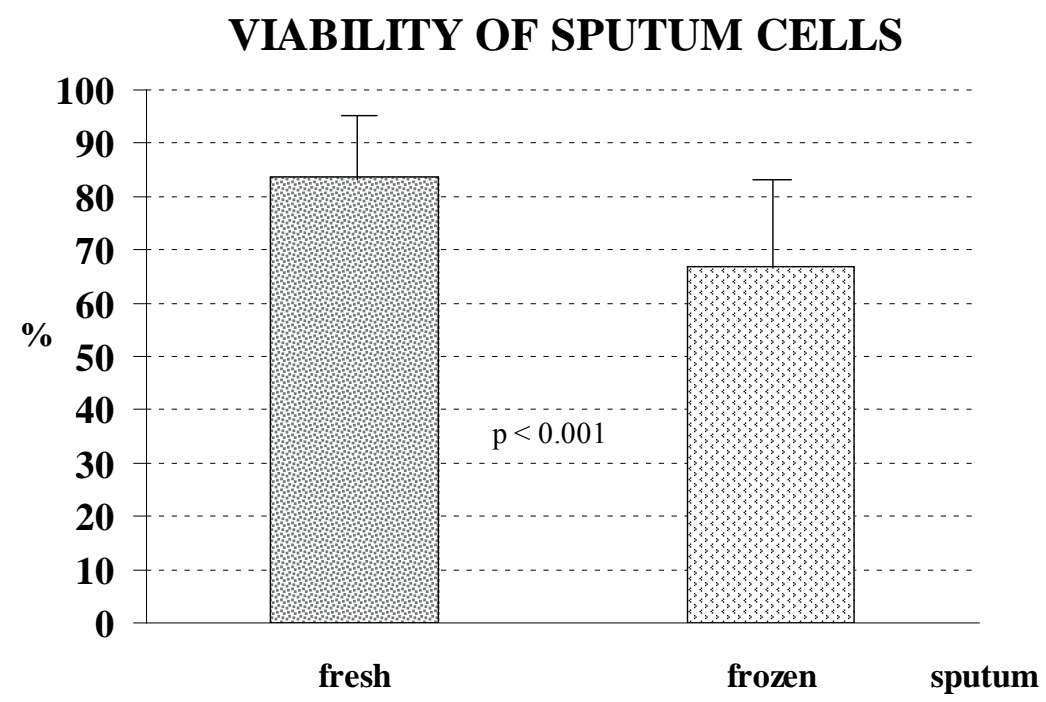

Figure 1. Upon thawing frozen sputum samples displayed relatively high cell viability, which was consistently lower than in freshly processed samples.

Table 2. Comparison between paired fresh and frozen sputum samples from induced and spontaneously obtained specimens

\begin{tabular}{|l|c|c|c|c|}
\hline \multirow{2}{*}{$\begin{array}{c}\text { Paired samples } \\
\text { fresh / frozen sputum }\end{array}$} & \multicolumn{2}{c|}{$\begin{array}{c}\text { Induced sputum } \\
\text { (n= 22) }\end{array}$} & $\begin{array}{c}\text { Spontaneous sputum } \\
\text { (n=22) }\end{array}$ \\
\cline { 2 - 5 } & $\begin{array}{c}\text { Intraclass correlation } \\
\text { coefficient }\end{array}$ & Sig. P & $\begin{array}{c}\text { Intraclass correlation } \\
\text { coefficient }\end{array}$ & Sig. P \\
\hline TCC & 0.49 & 0.081 & 0.71 & 0.004 \\
\hline Viability & -0.17 & 0.627 & 0.59 & 0.022 \\
\hline \% neutrophils & 0.55 & 0.049 & 0.84 & 0.000 \\
\hline $\begin{array}{l}\text { Absolute number of } \\
\text { neutrophils }\end{array}$ & 0.66 & 0.014 & 0.35 & 0.167 \\
\hline \% eosinophils & 0.82 & 0.000 & 0.97 & 0.000 \\
\hline $\begin{array}{l}\text { Absolute number of } \\
\text { eosinophils }\end{array}$ & 0.72 & 0.004 & 0.96 & 0.000 \\
\hline$\%$ macrophages & 0.49 & 0.080 & 0.88 & 0.000 \\
\hline $\begin{array}{l}\text { Absolute number of } \\
\text { macrophages }\end{array}$ & 0.35 & 0.186 & 0.80 & 0.000 \\
\hline
\end{tabular}

\section{Discussion}

Examination of sputum has proven itself to be a reliable non-invasive research method to assess the nature and level of inflammation in allergic airway diseases. However, it has not gained wide application as a routine method for the diagnosis and monitoring of asthma so far (12). One of the hurdles preventing its wider application is the time coupling of sputum collection to its subsequent processing in the existing protocols. This would certainly hamper the use of sputum in epidemiological field studies and in research designs requiring samples collection around the clock.

In this paper we have demonstrated that freezing sputum at the time of collection and processing it at a later stage is not significantly altering the results of the examination regarding its main cellular components: neutrophils, eosinophils and macrophages. We limited ourselves to cellular outcomes, as cells are most likely to be vulnerable to the freezing and thawing procedure. We have obtained fairly good concordance 
of the cellular measurements in the fresh and frozen sputum samples. The only characteristic slightly but consistently lower in the frozen samples was cell viability. We have no plausible explanation, as to why there should be such a marginal difference. It may be the case that there is a steady subpopulation of (aging?) cells, which are naturally more prone to acute physical stimuli. However, we have proven that it does not substantially alter the differential cell counts in the frozen specimens. It has been suggested before, that low cell viability may compromise the results of the examination. A threshold of $50 \%$ viability has been proposed as a safe low limit to reliable results ${ }^{13}, 14$. In our case, we must point out that we had a TCC $<50 \%$ in only one of the frozen spontaneous sputum samples, which is the cut-off suggested for reliability of the sputum cell measurements $(9,13)$.

In our study the mean viability $( \pm \mathrm{SD})$ of the fresh sputum samples was rather high: $83.8 \pm 11.8 \%$. A possible explanation for this result was the fact that we began the processing of our fresh specimen within 30 minutes after collection (current standard protocols would suggest processing within 2 hours of collection). The time lag between sputum collection and freezing was even shorter, as it was done immediately before the processing of the fresh portions of specimens. The mere preparation of the sputum sample for freezing is very brief and can be performed virtually anywhere. There is no time lag between sputum thawing and processing $(15,16)$.

Our work also provides evidence that examination of paired fresh and frozen induced sputum samples gives more consistent results than spontaneous ones. This is in line with the already established superiority of induced to spontaneous sputum in terms of reproducibility of cell counts and slide quality (8). We observed better quality of the cytospin slides of the induced sputum specimens (both fresh and frozen), compared with the spontaneous fresh and frozen samples, there were no significant differences between the agreement achieved with the spontaneous and induced fresh and frozen sputum samples in our study. This has enabled us to conduct studies at places far away from specialized laboratories (15) and to assess circadian rhythms of airway inflammation (16).

Examination of sputum continues to be a gold standard for non-invasive studies of airway pathology. New prospects have opened up with the continuously proposed many dozens of new biomarkers in sputum and the application of flow cytometry and different '-omics' approaches (17-19). However for the basic needs of distinguishing the major asthma, chronic obstructive pulmonary disease (COPD) and asthma-COPD overlap, standard cell counts are the indispensable outcome. Freezing of sputum samples upon their collection makes possible processing of this fragile biological material to be done at centralized laboratories at the convenience of their skilled technicians.

\section{CONCLUSIONS}

The protocol we have developed for freezing the sputum sample upon collection and examining it at a later stage at the convenience of the technician is yielding cell counts consistent with those of fresh sputum. Freezing sputum does not alter our understanding that induced sputum ensures higher quality of the slides and better reproducibility of the measurement.

\section{ACKNOWLEDGEMENT}

The authors would like to express their gratitude to Dimitrina Petkova for the technical support in the sputum processing. The study was supported by a grant of the European Academy of Allergology and Clinical Immunology.

\section{CONFLICT OF INTEREST}

The authors declare no conflict of interest.

\section{REFERENCES}

1. Brown HM. Treatment of chronic asthma with prednisolone; significance of eosinophils in the sputum. Lancet 1958; 2: 1245-1247.

2. Chodosh S, Zaccheo CW, Segal MS. The cytology and histochemistry of sputum cells. I. Preliminary differential counts in chronic bronchitis. Am Rev Respir Dis 1962; 85: 635-648.

3. O'Connell JM, Baird LI, Campbell AH. Sputum eosinophilia in chronic bronchitis and asthma. Respiration 1978; 35: 65-72.

4. Dor PJ, Ackerman SJ, Gleich GJ. Charcot-Leyden crystal protein and eosinophil granule major basic protein in sputum of patients with respiratory diseases. Am Rev Respir Dis 1984; 130: 1072-1077.

5. Gibson PG, Girgis-Gabardo A, Morris MM, Mattoli S, Kay JM, Dolovich J, et al. Cellular characteristics of sputum from patients with asthma and chronic bronchitis. Thorax 1989; 44: 693-699.

6. Fahy JV, Wong H, Liu J, Boushey HA. Comparison of samples collected by sputum induction and bronchoscopy from asthmatic and healthy subjects. Am J Respir Crit Care Med 1995; 152: 53-58. 
7. Popov T, Gottschalk R, Kolendowicz R, Dolovich J, Powers P, Hargreave FE. The evaluation of a cell dispersion method of sputum examination. Clin Exp Allergy 1994; 24: 778-783.

8. Pizzichini MM, Popov TA, Efthimiadis A, Hussack P, Evans S, Pizzichini E, et al. Spontaneous and induced sputum to measure indices of airway inflammation in asthma. Am J Respir Crit Care Med 1996; 154: 866-869. DOI:10.1164/ajrccm.154.4.8887576

9. Pavord ID, Sterk PJ, Hargreave FE, Kips JC, Inman MD, Louis R, et al. Clinical applications of assessment of airway inflammation using induced sputum. Eur Respir $J$ (Suppl) 2002; 37: 40s-43s. DOI: 10.1183/09031936.02 .00004002

10. Kips JC, Inman MD, Jayaram L, Bel EH, Parameswaran $\mathrm{K}$, Pizzichini MM, et al. The use of induced sputum in clinical trials. Eur Respir J (Suppl) 2002; 37: 47s-50s. PMID: 12361364

11. Popov TA, Pizzichini MM, Pizzichini E, Kolendowicz R, Punthakee Z, Dolovich J, et al. Some technical factors influencing the induction of sputum for cell analysis. Eur Respir J 1995; 8: 559-565. PMID:7664854

12. NHLBI/WHO Workshop Report: Global Strategy for Asthma Management and Prevention. 2002; NIH Publication No 02-3659: 3.

13. Pizzichini E, Pizzichini MM, Kidney JC, Efthimiadis A, Hussack P, Popov T, et al. Induced sputum, bronchoalveolar lavage and blood from mild asthmatics: inflammatory cells, lymphocyte subsets and soluble markers compared.
Eur Respir J 1998; 11: 828-834. PMID:9623684

14. Rutgers SR, Timens W, Kaufmann HF, van der Mark TW, Koeter GH, Postma DS. Comparison of induced sputum with bronchial wash, bronchoalveolar lavage and bronchial biopsies in COPD. Eur Respir J 2000; 15: 109-115. PMID:10678630

15. Popov TA, Shenkada M, Baleva M, Boyanovski B. Possible alterations in the airway local immunity and the tissue regeneration processes in the infection-free and allergen scanty antarctic environment. Bulgarian Antarctic Research. Life Sci 1999; 2: 93-96.

16. Popov TA, Shenkada MS, Tzoncheva AV, Pravtchanska MP, Mustakov TB, Dimitrov VD. Circadian changes in the sputum of asthmatic subjects and healthy controls. World Allergy Organ J 2008; 1: 74-78. DOI:10.1097/ WOX.0b013e3181752d02

17. Paone G, Leone V, Conti V, De Marchis L, Ialleni E, Graziani C, et al. Blood and sputum biomarkers in COPD and asthma: a review. Eur Rev Med Pharmacol Sci 2016; 20: 698-708. PMID: 26957273

18. Kasaian MT, Lee J, Brennan A, Danto SI, Black KE, Fitz L, et al. Proteomic analysis of serum and sputum analytes distinguishes controlled and poorly controlled asthmatics. Clin Exp Allergy 2018; 48: 814-824. DOI:10.1111/ cea. 13151

19. Gao J, Zhou W, Chen B, Lin W, Wu S, Wu F. Sputum cell count: biomarkers in the differentiation of asthma, COPD and asthma-COPD overlap. Int J Chron Obstruct Pulmon Dis 2017; 12: 2703-2710. DOI:10.2147/COPD.S142466 